\title{
Influence of Anthropogenic Chemical Factors on Immune Regulation in Petrochemical Production Workers with Cardiovascular System Pathology
}

\author{
A.S. Shirinkina ${ }^{1, *}$, I.N. Alikina ${ }^{1}$ and O.V. Dolgikh ${ }^{1}$ \\ ${ }^{I}$ Department of immunobiological diagnostic methods, Federal Scientific Center for Medical and Preventive Health \\ Risk Management Technologies, Perm, Russia \\ *Corresponding author. Email: shirinkina.ali@yandex.ru
}

\begin{abstract}
171 employees exposed to industrial anthropogenic chemical factors were examined. The sample was divided according to the principle of the presence of the cardiovascular diseases (CVD) (study group - 115 people) and their absence (comparison group - 56 people). For all employees, a chemical-analytical study of biological media for benzene content was carried out by gas chromatography. The study of cell phagocytosis was carried out using formalinized sheep erythrocytes. The content of IgG specific to benzene was determined by the allergosorbent method. Phenotyping of CD lymphocytes was performed on a flow cytometer by membrane immunofluorescence using a panel of labeled monoclonal antibodies (MoAbs) to membrane CD receptors. Determination of the TNFR, p53, Bcl-2, bax expression level was carried out using the corresponding MoAbs. Determination of total IgE, CA 199, PSA, interleukin-6, VEGF was performed by enzyme-linked immunosorbent assay (EIA method). The chemical and analytical studies identified an excess of the benzene content. Immunological studies revealed an increase in the index of phagocytic activity of cells. There were also significant changes in the CD indices of absolute and relative lymphocytes: the level of CD16+ cells of effectors increased, the level of CD19+, CD25+, CD95+ lymphocytes decreased, T-suppressor lymphocytes CD127- were activated, there was an increase in Annexin V-FITC + 7ADDnegative cells, TNFR, p53, bcl-2, bax. There was an increase in the general and specific sensitization of the body, as well as the level of tumor markers CA 19-9 and PSA, interleukin-6 and vascular endothelial growth factor VEGF. Significant changes in immunological parameters and the function of programmed cell death with simultaneous activation of sensitization processes reflected the peculiarities of the immune profile. These peculiarities formed disorders of the cardiovascular system functioning. Moreover, the increased level of specific sensitization to benzene emphasized the priority influence on the process of forming the workers' labour experience along with the age factor.
\end{abstract}

Keywords: anthropogenic chemical factors, immune regulation, petrochemical production workers, cardiovascular system pathology

\section{INTRODUCTION}

The petrochemical industry is the basic industry segment in the Russian Federation and it has a significant impact on the country's economy. The influence of harmful industrial anthropogenic factors on the health of workers employed in petrochemical industries are still poorly understood and primarily concern workers of the key chemical engineering occupations. [1]

The oil industry is quite dangerous for the health despite the significant improvement in working conditions over the past 20-30 years [1]. Amid the combined impact of production factors being hard physical labor and exposure to chemicals, increased neuro-emotional stress is the main cause of comorbid conditions. In 2014, the level of occupational morbidity 
was also higher than the average in Russia and amounted to 2.78 versus 1.74 cases per 10 thousand workers [2].

The main diseases of oil workers include the following: diseases of the musculoskeletal system, cardiovascular diseases (CVD), nervous system diseases, digestive system diseases. Meanwhile, the mortality of the economically active population is majorly caused by cardiovascular diseases (CVD) [3]. It is believed that petrochemical products affect high mortality caused by CVD diseases and may be due to exposure to aromatic hydrocarbons [4].

The most toxic of them is benzene. This substance in high concentrations has a drug-like impact on the central nervous system, and with systematic action of small doses it is poisonous for blood and hematopoietic organs $[5,6]$. It has been found that the effect of benzene leads to a decrease in the level of $\mathrm{T}$ - and $\mathrm{B}$ lymphocytes circulation and lymphocyte proliferation inhibition [7]. First of all, the T-system of immunity suffers due to the fact that T-lymphocytes are distinguished by the highest content of microsomal cytochromes P-450, which are involved in the biotransformation of xenobiotics, and in particular benzene.

Preserving professional health and longevity with the help of modern technologies reducing the level of morbidity and injuries is an urgent task of society, a significant function of the state and the basis of its social policy since the economic growth of the state is associated with the able-bodied population $[8,9]$.

The aim of this work is to study the impact of negative factors of petrochemical production on the immunity of workers with cardiovascular pathology.

\section{MATERIALS AND METHODS}

An in-depth medical study was carried out on 171 people aged from 23 to 60 and employed in oil production. The sample was divided into workers with a history of CVD pathology and workers with no CVD diseases. The study group included 115 people aged $45.74 \pm 0.82$ and working as operators in the petrochemical industry, with a history of such diseases as vegetative-vascular dystonia, varicosity and peripheral artery diseases. The control group consisted of 56 people aged $33.62 \pm 0.93$, working in the company's administration and being conditionally healthy, having no history of diseases associated with CVD pathology. Benzene is the main harmful chemical factor for workers in the petrochemical industry (hazard class 2).

All men underwent chemical-analytical analysis of biological media for the content of chemicals characteristic of petrochemical production (benzene).
The analysis was carried out using the method of gas chromatographic quantitative determination of aromatic hydrocarbons in biological media (blood) according to MUK 4.1.765-99 [10].

The study of the phagocytic activity of cells was carried out using formalinized sheep erythrocytes as objects of phagocytosis.

Determination of total immunoglobulin class E ( $\operatorname{IgE})$ in blood serum was carried out using enzyme-linked immunosorbent assay.

An allergosorbent test with an enzyme label determined the change in the content of a pollutant (benzene) targeted immunoglobulin of class $\mathrm{G}$ ( $\mathrm{IgG}$ ). Specific reagins were identified using peroxidaseconjugated antibodies.

Phenotyping of CD lymphocytes was performed on a Becton Dickinson FACSCalibur flow cytometer using the CellQuest.Pro universal program. Populations and subpopulations of lymphocytes (CD16+, CD19+, CD25+, CD95+, CD127-) were determined by membrane immunofluorescence using a panel of labeled monoclonal antibodies to membrane CD receptors (Becton Dickinson, USA), with a total of at least 10,000 events recorded.

To determine the level of expression to tumor necrosis factor- $\alpha 1$ (TNFR-trumor necrosis factor receptor 1 ), we used a cytofluorometric method based on the interaction of the corresponding monoclonal antibodies (Becton Dickinson, USA) with the membrane receptor to TNF $\alpha$.

The level of proteins Bcl-2, bax expression was determined using the appropriate MoAbs (Becton Dickinson, USA) and simultaneous procedure of negative isotopic control.

The intracellular marker of apoptosis p53 protein was determined using MoAbs (Becton Dickinson, USA) against the $\mathrm{p} 53$ protein conjugated to PE.

The lymphocytes apoptosis was registered by a method based on determining the expression on the outer membrane of phosphatidylserine molecules using annexin V conjugated with FITC (Annexin V-FITC) and DNA fragmentation using the vital dye 7-AAD (7amino-actinomycin D) (Becton Dickinson, USA).

Markers of cell proliferation (CA 19-9, PSA), cytokines (interleukin-6) and vascular endothelial growth factor (VEGF) were determined using enzyme-linked immunosorbent assay (test system of "Vector-Best" company, Novosibirsk) on an "Elx808IU" analyzer.

The methods of mathematical statistics involved the Microsoft ${ }^{\circledR}$ Office Excel 2003 program and the Statistica 6.0 application package. (StatSoft, USA) were used for the statistical processing of the research results. Statistical analysis of the data was carried out by methods of descriptive statistics and samples 
comparison (using Student's t test and Mann-Whitney $\mathrm{U})$. The nature of the statistical distribution over the samples was established by the goodness-of-fit test $\chi 2$. Qualitative data were presented as absolute or relative (\%) frequencies, and quantitative features were presented as $\mathrm{M} \pm \mathrm{m}$ (arithmetic mean \pm mean error). The significance of differences between the groups was considered significant at $\mathrm{p} \leq 0.05$.

\section{RESULTS}

When distributing the sample according to the presence and absence of CVD pathology, differences were found in such parameters as age and work experience. Work experience in the study group was two times lower $(\mathrm{P} \leq 0.05)$ than in the comparison group, while the age of workers with CVD (cardiovascular diseases) in this group was 1.4 times higher $(\mathrm{P} \leq 0.05)$, which indicated the role of age and labor in the development of CVD.

According to the results of chemical and analytical studies of the content of hydrocarbons typical for petrochemical production, there was a significant excess of the reference level of benzene in the blood both in the study and comparison groups (by 64.8 and $61.4 \%$, respectively) $(\mathrm{P} \leq 0.05)$. In the study group, the level of benzene in the blood was 1.09 times higher than in the comparison group $(\mathrm{P} \leq 0.05)$ (Table 1$)$.

According to the results of immunological studies in the study group, the following significant differences were revealed in the indicators of phagocytic activity relative to the comparison group: an increase in the percentage of phagocytosis by 1.08 times, the phagocytic number by 1.11 times and absolute phagocytosis by 1.13 times $(\mathrm{P} \leq 0.05)$.

Table 1. Comparative assessment of benzene content in blood of workers employed in petrochemical production

\begin{tabular}{l|l|l|l|}
\hline Indicator & Reference interval & Study group $(\mathrm{n}=115)$ & Comparison group $(\mathrm{n}=56)$ \\
\hline Benzene [blood], $\mu \mathrm{g} / \mathrm{cc}$ & 0.0 & $0.000486 \pm 0.000074^{*} /^{* *}$ & $0.000445 \pm 0.000116$ \\
\hline Note: & \\
$*-$ - the difference is significant relative to the reference interval $(\mathrm{p} \leq 0.05)$. \\
$* *-$ the difference is significant relative to the comparison group $(\mathrm{p} \leq 0.05)$.
\end{tabular}

In addition, there were significant changes in the $\mathrm{CD}$ values of absolute and relative lymphocytes. In the study group relative to the comparison group, the level of CD16+ cells of effectors, absolute (1.1 times higher) and relative (1.2 times higher) lymphocytes responsible for antitumor immunity was increased; levels of CD19+ absolute (1.2 times lower) and relative (1.25 times lower) lymphocytes $(\mathrm{P} \leq 0.05)$ were decreased.

There was a decrease in CD25+ absolute (1.3 times lower) and relative (1.34 times lower) lymphocytes (responsible for the efficiency of the cellular response) relative to the comparison group. Along with this, $58.2 \%$ of men in the study group showed a decrease in the indicator relative to the reference level. Both in the study group and in the comparison group with a pronounced decrease in the cell death receptor CD95+, the absolute and relative lymphocytes went beyond the lower limit of the norm $(\mathrm{P} \leq 0.05)$. At the same time, the study group showed a more pronounced decrease in the relative (below 1.23 times) and absolute (below 1.25 times) the number of lymphocytes relative to the comparison group.

The CD127-value of absolute and relative lymphocytes with high suppressive activity in the study groups differed by many times higher values relative to the upper limit of normal. Notably, in the comparison group there was a more pronounced increase in this indicator (up to 1.79 times) compared to the study group $(\mathrm{P} \leq 0.05)$.

In terms of Annexin V-FITC+7ADD-negative cells, in both study groups there was a significant twofold excess of the upper limit of normal. In the study group with CVD diseases, this indicator was 1.2 times higher than in the comparison group, which indicated a predominant cell death by apoptosis $(\mathrm{p} \leq 0.05)$.

In terms of the p53 transcription factor, both study groups also had a multiple (6.8 times for the study group and 6.7 times for the comparison group) significant excess relative to the upper limit of normal $(\mathrm{P} \leq 0.05)$. In the study group, there was an excess of this indicator by 1.3 times when compared with the comparison group $(\mathrm{P} \leq 0.05)$.

The value of the membrane factor TNFR in both groups exceeded the upper limit of normal by 2.7 times, and the values were higher than in the comparison group by 1.01 times relative to the study group $(\mathrm{P} \leq 0.05)$.

For the antiapoptotic factor that controls the aggression of the immune response $\mathrm{Bcl}-2$, there was a similar increase in both groups relative to the upper normal limit $(\mathrm{P} \leq 0.05)$.

The apoptosis receptor bax was characterized by a significant increase in both groups relative to the upper limit of the norm (1.3 times), while this indicator in the study group was 1.01 times higher than in the comparison group $(\mathrm{P} \leq 0.05)$.

It was noted that the level of CA 19-9 and PSA in the study group exceeded the identical indicators in the comparison group by 1.15 and 1.4 times respectively $(p \leq 0.05)$, although both indicators fell within normal range. 
The level of vascular endothelial growth factor VEGF $(\mathrm{P} \leq 0.05)$ increased 1.14 times compared to the comparison group $(\mathrm{p} \leq 0.05)$, which in turn indicated the disorders.

The interleukin-6 level indicator had significant $(\mathrm{P} \leq 0.05)$ differences between the groups falling within the normal range, while the comparison group had a more reduced level of this indicator $(1.3$ times $)$ when compared with the study group (Table 2 ).

A significant increase by 1.25 times $(p \leq 0.05)$ of the level of general sensitization (total $\mathrm{IgE}$ ) of the study group was established in relation to the comparison group.

At the same time, $45.2 \%$ of workers in the study group showed an increased level of specific sensitization of the body to benzene according to the criterion of class $\mathrm{G}$ immunoglobulin compared with the age norm. Additionally, the level of specific sensitization to benzene according to the $\mathrm{IgG}$ criterion was significantly increased by 1.1 times in relation to the comparison group $(\mathrm{P} \leq 0.05)$ (Table 3$)$.

A significant increase by 1.25 times $(p \leq 0.05)$ of the level of general sensitization (total $\mathrm{IgE}$ ) of the study group was established in relation to the comparison group.

At the same time, $45.2 \%$ of workers in the study group showed an increased level of specific sensitization of the body to benzene according to the criterion of class $\mathrm{G}$ immunoglobulin compared with the age norm. Additionally, the level of specific sensitization to benzene according to the IgG criterion was significantly increased by 1.1 times in relation to the comparison group $(\mathrm{P} \leq 0.05)$ (Table 3$)$.

Table 2. Immunological indicators of workers employed in petrochemical production

\begin{tabular}{|c|c|c|c|}
\hline Indicator & Reference interval & Study group ( $n=115)$ & Comparison group $(n=56)$ \\
\hline Percentage of phagocytosis, $\%$ & $35-60$ & $53.261 \pm 1.82^{* *}$ & $49.089 \pm 2.204$ \\
\hline Phagocytic number, c.u. & $0.8-1.2$ & $1.025 \pm 0.051^{\star \star}$ & $0.920 \pm 0.059$ \\
\hline Absolute phagocytosis, $109 / \mathrm{dm}^{3}$ & $0.964-2.988$ & $2.330 \pm 0.152^{\star *}$ & $2.061 \pm 0.215$ \\
\hline CD16+CD56+- Iymphocytes. rel., \% & $5-27$ & $17.589 \pm 1.924^{\star \star}$ & $15.750 \pm 2.642$ \\
\hline CD16+CD56+- lymphocytes. abs., $10^{9} / \mathrm{dm}^{3}$ & $0.09-0.59$ & $0.387 \pm 0.059^{\star *}$ & $0.348 \pm 0.08$ \\
\hline $\mathrm{CD}^{+}{ }^{+} \mathrm{CD} 19^{+}$- lymphocytes. rel., $\%$ & $6-25$ & $9.661 \pm 1.096^{\star \star}$ & $12.083 \pm 3.157$ \\
\hline CD3 ${ }^{+}$CD19+- lymphocytes. abs., $10^{9} / \mathrm{dm}^{3}$ & $0.09-0.66$ & $0.214 \pm 0.032^{* *}$ & $0.256 \pm 0.066$ \\
\hline CD3+CD127- lymphocytes. rel., \% & $0.8-1.2$ & $3.514 \pm 1.028^{* / * *}$ & $6.307 \pm 2.112$ \\
\hline CD3+CD127- lymphocytes. abs., $10^{9} / \mathrm{dm}^{3}$ & $0.015-0.04$ & $0.078 \pm 0.025^{\star} / * \star$ & $0.140 \pm 0.046$ \\
\hline CD3+CD25+- lymphocytes. rel., \% & $13-24$ & $11.509 \pm 2.294^{*} / * \star$ & $15.409 \pm 3.879$ \\
\hline CD3+CD25+- lymphocytes. abs., $10^{9} / \mathrm{dm}^{3}$ & $0.19-0.56$ & $0.253 \pm 0.055^{\star \star}$ & $0.330 \pm 0.094$ \\
\hline $\mathrm{CD}^{+}{ }^{+} \mathrm{CD} 5^{+}-$lymphocytes. rel., \% & $39-49$ & $21.745 \pm 3.283^{*} / * \star$ & $26.727 \pm 5.261$ \\
\hline $\mathrm{CD}^{+}{ }^{+} \mathrm{CD} 95^{+}$- lymphocytes. abs., $10^{9} / \mathrm{dm}^{3}$ & $0.63-0.97$ & $0.450 \pm 0.07^{\star} /^{\star \star}$ & $0.562 \pm 0.125$ \\
\hline Annexin V-FITC+7AAD negat. cells, \% & $1.5-2.5$ & $4.912 \pm 1.669 * / * *$ & $4.288 \pm 1.872$ \\
\hline p53, \% & $1.2-1.8$ & $12.265 \pm 1.913^{* / * *}$ & $12.095 \pm 3.448$ \\
\hline CD16+CD56+- lymphocytes. rel., \% & $5-27$ & $17.589 \pm 1.924^{* \star}$ & $15.750 \pm 2.642$ \\
\hline CD16+CD56+- lymphocytes. abs., $10^{9} / \mathrm{dm}^{3}$ & $0.09-0.59$ & $0.387 \pm 0.059^{* *}$ & $0.348 \pm 0.08$ \\
\hline CD3+CD19+- lymphocytes. rel., \% & $6-25$ & $9.661 \pm 1.096^{\star *}$ & $12.083 \pm 3.157$ \\
\hline CD3+CD19+- lymphocytes. abs., $10^{9} / \mathrm{dm}^{3}$ & $0.09-0.66$ & $0.214 \pm 0.032^{* *}$ & $0.256 \pm 0.066$ \\
\hline TNFR, \% & $1-1.5$ & $4.099 \pm 1.036^{*} / * \star$ & $4.157 \pm 1.72$ \\
\hline $\mathrm{Bcl}-2, \%$ & $1-1.5$ & $2.469 \pm 0.992^{*}$ & $2.955 \pm 1.213$ \\
\hline Bax, \% & $5-9$ & $12.265 \pm 1.913^{*} / * *$ & $12.095 \pm 3.448$ \\
\hline CA-19-9, units/ml & $0-35$ & $7.289 \pm 1.482^{\star *}$ & $6.331 \pm 1.446$ \\
\hline$\Pi \mathrm{CA}, \mathrm{ng} / \mathrm{ml}$ & $0-3.9$ & $0.621 \pm 0.151^{* *}$ & $0.466 \pm 0.079$ \\
\hline VEGF, pg/ml & $10-700$ & $208.048 \pm 35.685^{\star *}$ & $182.462 \pm 49.02$ \\
\hline Interleukin-6, pg/ml & $0-10$ & $2.511 \pm 0.459^{* *}$ & $1.888 \pm 0.601$ \\
\hline
\end{tabular}

Table 3. Indicators of hypersensitivity of workers employed in petrochemical production

\begin{tabular}{l|l|l|l|}
\hline Indicator & Reference interval & Study group $(\mathrm{n}=115)$ & Comparison group $(\mathrm{n}=56)$ \\
\hline total $\lg \mathrm{E}, \mathrm{ME} / \mathrm{cm}^{3}$ & $0-149.9$ & $143.16 \pm 47.596^{* *}$ & $114.624 \pm 44.696$ \\
\hline $\lg \mathrm{G}_{\text {spec }}$ to benzene, c.u. & $0-0.15$ & $0.177 \pm 0.027^{\star * *}$ & $0.163 \pm 0.036$ \\
\hline $\begin{array}{l}\text { Note: } \\
*-\text { the difference is significant relative to the reference interval }(\mathrm{p} \leq 0.05) .\end{array}$ \\
$\begin{array}{l}* * \text { - the difference is significant relative to the comparison group }(\mathrm{p} \leq 0.05) .\end{array}$
\end{tabular}




\section{DISCUSSION}

A number of authors concluded with the changes in the cardiovascular system during the prolonged exposure of oil workers to petroleum products based on the studies of the functional state of the cardiovascular system. Changes were expressed in hypertension, coronary heart disease, arterial hypertension [11]. Among the complaints indicating changes in the function of internal organs, heart pain $(52.8 \%)$ took the lead [12].

As can be seen from the literature, indicators of immunological reactivity in workers revealed a change in all links of immunity. Having evaluated the frequency of violations, we revealed multidirectional changes in relation to the reference values and the comparison group. On CD95+ example, a significant increase in antigens could be observed in the main group compared to the comparison group in both studies [13].

\section{CONCLUSION}

Thus, violations of the cellular link of immunity, specifically, an increase in the phagocytic cells' activity, an increase in the level of CD16+ effector cells, a decrease in the level of CD19+, CD25+, CD95+ lymphocytes, activation of CD127-T-suppressor lymphocytes, increased Annexin V-FITC + 7ADD-negative cells, TNFR. p53. bcl2. bax were revealed in workers employed in petrochemical production. There was an increase in the general and specific sensitization of the body, as well as the level of tumor markers CA 19-9 and PSA, interleukin-6 and vascular endothelial growth factor VEGF, which in turn characterizes changes in the parameters of immune homeostasis and is responsible for the formation of cardiovascular disorders under the influence of negative anthropogenic industrial chemical factors.

\section{REFERENCES}

[1] L.R. Karimova, Z.F. Gimaeva, V.A. Kaptsov et al., Assessment of risk for health hazard in petrochemical production workers exposed to chemical factor, Public health and life environ. 1 (2012) 67-69.

[2] R.G. Oganov, I.N. Denisov, V.I. Simanenkov et al., Comorbid pathology in clinical practice. Clinical recommendations, Cardiovasc. therapy and prevent. 16(6) (2017) 5-56.

[3] G.I. Shamsiakhmetova, Occupational diseases in the oil industry, Young sci. 16 (2016) 460-463.

[4] A.S. Baidina, A.E. Nosov, V.B. Alekseev, Metabolic syndrome risk factors among oil production enterprise employees, Hum. Ecol. 16 (2016) 460-463.
[5] N.V. Zaitseva, M.A. Zemlyanova, A.V. Tarantin, Human protein blood count disorders under impact of aromatic hydrocarbons, Hum. Ecol. 7 (2013) 15-26.

[6] R.A. Orudzhov, R.E. Dzhafarova, Changes in the nervous system state and peripheral blood parameters under benzene intoxication during an experiment, Health Risk Anal. 4 (2017) 108-116.

[7] J.B. Ward, D.A. Hastings, E.B. Whorton et al., Mutant lymphocyte frequencies in workers in petrochemical plant, Environ. and Mol. Mutagenes 28(29) (1997) 55.

[8] On the sanitary and epidemiological situation in the Russian Federation in 2018: State report, Moscow, 2019.

[9] N.F Izmerov, The national system of occupation health as a basis for promoting working population health in Russia, Healthcare of the Russ. Fed. 1 (2008) 7-8.

[10] Measurement of mass concentrations of chemical elements in biological media (blood, urine) by inductively coupled plasma mass spectrometry, MUC 4.1.3230-14. Retrieved from: http://docs.cntd.ru/document/495856222

[11] R.F. Kamilov, R.N. Yapparov, V.M. Samsonov et al., Health condition of the workers involved in the production of petrochemical rubber, Med. Bull. of Bashkortostan 5 (2009) 10-17.

[12] G.G. Badamshina, A.B. Bakirov, A.E. Bakirova et al., Characteristics of changes in peripheral blood indicators in petrochemical workers, Med. Bull. of Bashkortostan 4 (2013) 15-19.

[13] G.V. Timasheva, A.B. Bakirov, E.T. Valeyeva et al., The laboratory markers of early metabolic disorders in workers of rubber articles industry, Clin. Labor. Diagnost. 7 (2015) 31-35. 